\title{
dossiê
}

DOI: 10.11606/issn.2318-8855.v6i6p225-241

\section{Uma Carta aberta ao Futuro: Horizontes de expectativa e Revolução em “Carta aberta aos operários" de Vladimir Maiakóvski (1918)}

Ana Carolina Lebre dos Santos ${ }^{*}$

Resumo: Tendo em vista as transformações na relação dos homens com o tempo a partir dos séculos XVII e XVIII, este breve artigo pretende compreender as concepções de revolução e de futuro presentes na Carta Aberta aos Operários, uma das cartas escritas pelo poeta russo Vladimir Maiakóvski pouco após a Revolução de Outubro. A inauguração de um tempo novo, em aberto, bem como a crença na atuação consciente dos homens sobre a história e a ruptura com o passado caracterizam a compreensão moderna de revolução, como pontuam, dentre outros, Reinhart Koselleck e Hannah Arendt. Elementos dessa nova percepção da temporalidade histórica aparecem na carta de Maiakóvski através de sua esperança em um futuro melhor, projetado na continuidade da revolução. Após a análise da carta, pretendeuse, por fim, comparar as expectativas de Maiakóvski no início do processo revolucionário com sua desilusão diante das experiências concretas do Estado Soviético. Realizando um breve panorama sobre a situação de outros poetas, concluiu-se que, se o futuro esteve em aberto desde o século XVIII, o processo da Revolução Russa no século XX demonstrou que os homens, a exemplo de Maiakóvski, não conseguem prever esse futuro e nem construí-lo por completo.

Palavras-Chave: Vladimir Maiakóvski; Tempo; Futuro; Revolução; Revolução Russa.

*Graduanda em História pela Faculdade de Filosofia, Letras e Ciências Humanas da Universidade de São Paulo. Contato: ana.lebre@usp.br. 


\section{Novos Construtores}

Em 1918, ou seja, pouco após a tomada do Palácio de Inverno pelos bolcheviques, o escritor, poeta e roteirista russo Vladimir Constantinovitch Maiakóvski publicou a sua Carta Aberta aos Operários $^{1}$ na que seria a primeira e única edição da Gazeta Foutouristov, um dos jornais dos futuristas. Ao passo que muitos artistas se aproximavam da revolução, a Rússia adotava um novo calendário, o gregoriano (CHERMAN, Alexandre; VIEIRA, Fernando, 2008, p. 81 ) indicando que o tempo de ruptura expresso em Outubro deveria ser acompanhado por uma mudança na marcação temporal.

Em especial os artistas ligados ao movimento futurista passaram a associar a defesa do futuro expressa em sua arte à defesa do próprio movimento revolucionário. Como Maiakóvski afirmou em 1922, “o futurismo não existiu na Rússia como corrente única, claramente formulada" antes da Revolução de Outubro (MAIAKÓVSKI [1922]1984, p. 163). Foi durante o processo revolucionário que o movimento artístico se reconfigurou e alguns de seus membros, como Maiakóvski, se aproximaram do Partido Comunista e utilizaram a arte para expressar seu apoio aos bolcheviques². "A Revolução de Outubro separou o nosso grupo de numerosos grupos pseudofuturistas, que se afastaram da Rússia revolucionária e nos congregou no grupo dos 'comunistas-futuristas"', destaca Maiakóvski ([1922] 1984, p.163).

Os futuristas que se alinharam à Revolução de Outubro defenderam, de modo geral, que a ruptura com o passado, a criação de novas formas artísticas e o incentivo à urbanização deveriam ocorrer em nome do compromisso com as transformações sociais. Diferentemente, por exemplo, do futurismo italiano expresso por Marinetti, o futurismo de Maiakóvski detinha um "acento antiimperalista inconfundível e um apelo à rebelião social", segundo Ângelo Maria Ripellino (1971 apud SCHNAIDERMAN, 1984, p. 24).

\footnotetext{
1 Todas as citações à "Carta Aberta aos Operários" e aos demais textos de Maiakóvski foram extraídas da obra de SCHNAIDERMAN (1984).

2 Em nota, Boris Schnaidermam explica que, apesar de o futurismo ter sofrido uma hostilidade constante por parte do partido comunista, algumas de suas correntes tiveram o apoio oficial do governo revolucionário, ao menos no início da revolução. Maiakóvski integrava o chamado grupo dos "cubofuturistas" que entre 1918-1919 contou com o patrocínio do Comissariado da Instrução Popular. (SCHNAIDERMAN, 1984, p. 69).
} 
Uma Carta aberta ao Futuro: Horizontes de expectativa e Revolução em “Carta aberta aos operários" de Vladimir Maiakóvski (1918)

A maior parte dos poemas e textos de Maiakóvski estão carregados de uma esperança latente em um futuro novo, no qual os homens viveriam apenas sob "imensos sóis" (MAIAKÓVSKI [1918], 1984, p.120). A presença dessa fé no amanhã em sua obra se relaciona com uma transformação na maneira como os homens passaram a vivenciar o tempo após os séculos XVII e XVIII. Segundo Reinhart Koselleck, a partir desse momento o futuro deixou de ser a repetição reiterativa do passado e se tornou, progressivamente, um horizonte no qual os homens passaram a projetar o progresso e o melhoramento da vida terrena (2006).

O conceito de "progresso" só foi criado no final do século XVIII, quando se procurou reunir grande número de novas experiências dos três séculos anteriores. O conceito de progresso único e universal nutria-se de muitas novas experiências individuais de progressos setoriais, que interferiam com uma profundidade cada vez maior na vida quotidiana e que antes não existiam. [...] A novidade era a seguinte: as expectativas para o futuro se desvincularam de tudo quanto as antigas experiências haviam sido capazes de oferecer. (KOSELLECK, 2006, p. 318).

Maiakóvski foi um dos personagens centrais na criação e difusão das ideias de um novo tempo ${ }^{3}$, no início da Revolução de Outubro. Ele, porém, só pôde esperar novas e melhores experiências do futuro, pois presenciava esse contexto de profunda transformação do próprio significado do tempo- do futuro e do passado.

Logo no início de sua carta aos operários, Maiakóvski afirma que “Os palácios do luxo de ontem estão aí qual esqueletos calcinados" e que "As cidades devastadas esperam novos construtores" pois "o turbilhão revolucionário arrancou dos espíritos as raízes nodosas da escravidão" (MAIAKÓVSKI, [1918] 1984, p. 119). Dessas frases, pode-se perceber a associação que Maiakóvski realiza entre futuro e rompimento com o passado. O peso das experiências anteriores-para ele "raízes nodosas da escravidão"- não são suficientes para impedir uma nova "semeadura grandiosa", completamente distinta e, mais do que isso, melhor. De acordo com Hans Meyerhoff,

3 Entre 1919 e 1922, Maiakóvski trabalhou na ROSTA, a agência de informação e telegrafia oficial do governo revolucionário, criando a maior parte dos cartazes de propaganda durante a Guerra Civil, além de poemas e peças em homenagem à Revolução. De acordo com Renée Poznanski, Maiakóvski chegou a produzir mais de 700 cartazes durante sua atividade na ROSTA. (POZNANSKI, 1981, p. 122). 


\begin{abstract}
A ideia de progresso não foi inventada por teorias filosóficas, mas repousou como sabemos, nas sólidas experiências práticas das radicais mudanças que ocorreram no mundo moderno, primeiro como consequência das revoluções econômica e científica dos séculos dezessete e dezoito, e, depois, como resultado das mudanças até mesmo mais radicais iniciadas pela revolução industrial e tecnológica durante os dois últimos séculos. (MEYERHOFF, 1976, p.93).
\end{abstract}

Ao longo de toda a sua carta, Maiakóvski exprime a continuidade dessa associação entre tempo e progresso no início do século $X X$, enfatizando suas expectativas sobre o futuro da revolução. Claramente, a atmosfera em 1918 era incerta, não só pelo acirramento das tensões internas e pelos embates sobre o caráter do Governo Bolchevique, como também pelas consequências da Primeira Guerra Mundial, a exemplo dos conflitos com os antigos aliados, os ingleses, e as despesas militares necessárias à proteção do novo regime revolucionário. No início do texto, Maiakóvski se preocupa com a herança deixada pela violência, afirmando que "O duplo incêndio da guerra e da revolução esvaziou as nossas almas e nossas cidades" (MAIAKÓVSKI, [1918] 1984, p. 119). A despeito desse impasse, a continuidade do processo revolucionário era, para o poeta, a solução dos entraves trazidos pelas "cidades devastadas".

Hannah Arendt, ao tentar apreender as mudanças nos significados de revolução, defende que uma das novidades do termo a partir do século XVIII foi a esperança de que os homens pudessem romper com a opressão social e buscar a liberdade em um novo "modo político de vida" (ARENDT, 2011, p. 61). A expectativa de Maiakóvski nos "novos construtores" (MAIAKÓVSKI, [1918] 1984, p. 119), ou seja, nos operários, traduz, justamente, essa maneira de encarar a revolução como uma novidade desejável.

Apenas onde existe esse pathos de novidade e onde a novidade está ligada à idéia de liberdade é que podemos falar em revolução. Evidentemente, isso significa que as revoluções não se resumem a insurreições vencedoras e que não é o caso de qualificar de revolução qualquer golpe de Estado e tampouco procurar revolução em qualquer guerra civil (ARENDT, 2011, p. 61).

Segundo Roman Jakobson, os escritos de Maiakóvski encarnavam a sua luta incansável contra um cotidiano sufocante. Sua angústia diante dos "limites fixos e estreitos" das 


\section{dossiê}

Uma Carta aberta ao Futuro: Horizontes de expectativa e Revolução em “Carta aberta aos operários" de Vladimir Maiakóvski (1918)

experiências do passado o teriam levado a projetar a alegria no futuro e a associar o turbilhão revolucionário ao fim das "raízes nodosas da escravidão" (JAKOBSON, 2006, p.14).

A ideia de revolução defendida por Maiakóvski na Rússia no início do século XX seria, portanto, um sintoma da consolidação de um novo olhar sobre o tempo, "desconhecido antes das duas grandes revoluções no final do século XVIII" (ARENDT, 2011, p. 56) e no qual o futuro deixou de ser contemporâneo ao passado, como o era nas concepções temporais parcialmente cíclicas, associadas aos retornos naturais e religiosos (WHITROW, 1993, p. 68).

Maiakóvski enxerga o passado como um quadro de referências a ser rompido e não como um modelo para os passos seguintes da humanidade. De fato, ele pergunta aos operários: "Com que edifícios fantásticos hão de cobrir o lugar dos incêndios de ontem?" (MAIAKÓVSKI, [1918] 1984, p. 119), justamente porque o futuro está em aberto.

\section{Revolução do Espírito: contrução de um novo tempo}

Assim como Arendt, Koselleck também discute as múltiplas transformações do conceito de revolução. Para ele, a associação entre processo revolucionário e emancipação esteve intrinsecamente relacionada à emergência da novidade do futuro e sua separação das experiências do passado. Após a Revolução Francesa, a ideia de movimento cíclico, antes associada ao conceito, teria perdido força e sido progressivamente substituída por uma concepção moderna de revolução, na qual o futuro é "a tal ponto desconhecido, que conhecêlo e dominá-lo tornou-se uma contínua tarefa política" (KOSELLECK, 2006, p.68 e 69).

Associadas a um objetivo e ao planejamento do futuro, as revoluções modernas teriam também, de acordo com Koselleck, a pretensão de se tornarem universais e permanentes. Quando Maiakóvski escreve em sua carta que se dirige àqueles que "amanhã se tornarão os donos do mundo inteiro" (MAIAKÓVSKI, [1918] 1984, p. 119), ele acredita que as transformações revolucionárias na Rússia irão se estender para toda a humanidade, reforçando o argumento de Koselleck. "A partir da criação de diferentes Internacionais o 
conceito de revolução universal passou a fazer parte dos programas de ação política imediata" (KOSELLECK, 2006, p. 73).

$\mathrm{Na}$ busca por um futuro planejado, as revoluções modernas passariam a projetar transformações sociais profundas, para além de mudanças pontuais. Maiakóvski, antes de tudo, enxergava na arte e na propaganda um lugar privilegiado para a consolidação da revolução universal. Segundo ele, as rupturas com o passado e a construção do futuro dependiam de uma arte combativa, de modo que as transformações só estariam completas quando a revolução atingisse o espírito dos homens. Como coloca Renée Poznanski, Maiakóvski celebrou, em todos os seus poemas, uma revolução que não teria sido concluída (POZNANSKI, 1981, p. $120 .^{4}$

Em sua Carta Aberta aos Operários ele defende expressamente que a revolução política de 1917 deveria ser acompanhada por uma revolução nas artes. "A Revolução do conteúdosocialismo-anarquismo é inconcebível sem a revolução da forma: o futurismo" (MAIAKÓVSKI [1918] 1984, p.120). Para Poznanski, quando Maiakóvski sugere que no futuro "talvez os pintores transformem a poeira cinzenta das cidades em arco-iris centicores" ele está reiterando o fato de que é somente da associação entre política e arte que uma revolução se torna completa e profunda (POZNANSKI, 1981, p. 120). ${ }^{5}$

É a partir de março de 1918, com a aparição do único número da Gazeta Foutouristov (A Gazeta dos Futuristas) que se exprime claramente a exigência dos futuristas de atingir um estatuto privilegiado no Estado revolucionário. Nesse número, Bourliuk, Kamenski e Maiakóvski se declararam como os verdadeiros revolucionários da arte e Maiakóvski dirigiu uma "Carta Aberta aos Operários", na qual zombou da arte antiga ainda proposta aos trabalhadores e se pronunciou a favor de uma Revolução Espiritual. (POZNANSKI, 1981, p. 120, tradução nossa). ${ }^{6}$

\footnotetext{
4 [La Révolution qu'il célébrait pourtant dans chacun de ses poèmes n'avait pas été jusqu'au bout]

5 Poznanski traduz alguns trechos da Carta aberta aos Operários (Lettre Ouverte aux Ouvriers), que retira diretamente da versão em russo da Gazeta Foutouristov. Os trechos citados são semelhantes à tradução para o português feita por Boris Schnaiderman. [ il se pourrait que les artistes transforment la poussière grise des villes en arcs-au-ciel multicolores].

6 [C'est à partir de mars 1918, avec l'apparition de l'unique numéro de Gazeta Foutouristov (La Gazette des
} 
Uma Carta aberta ao Futuro: Horizontes de expectativa e Revolução em “Carta aberta aos operários" de Vladimir Maiakóvski (1918)

A perspectiva de que o futuro em aberto poderia ser construído e pensado pelos homens indica que os revolucionários modernos acreditavam na atuação consciente dos homens sobre seu próprio futuro. Maiakóvski enxerga que "os novos construtores" irão transformar as cidades e o mundo, justamente porque podem transformar o tempo. Como destacou Roman Jakobson, uma das principais tarefas que Maiakóvski delegava aos artistas, era a de "apressar o tempo". Na medida em que o "eu do poeta é um aríete que golpeia o futuro proibido", todos os que assim de autodenominassem deveriam, para Maiakóvski, auxiliar na construção de um novo futuro e na destruição das experiências antigas (JAKOBSON, 2006, p.2 e 16).

Essa aceleração do tempo proposta por Maiakóvski era, de certa forma, uma realidade vivida pelos homens desde as primeiras revoluções modernas. Para além dos impactos das chamadas revoluções tecnológicas e industriais, que constribuíram significativamente para que o tempo passasse a ser visto como "um precioso elemento de riqueza" (MEYERHOFF, 1976, p.95), uma das grandes transformações em curso se refere ainda ao abandono do “horizonte 'natural' da história” (KOSELLECK, 2006, p.70). Segundo Koselleck, os revolucionários do mundo moderno procuraram apressar o tempo para abreviar seu encontro com o futuro grandioso que esperavam. "A aceleração do tempo, antes uma categoria escatológica, torna-se, no século XVIII, uma tarefa do planejamento temporal, antes ainda que a técnica assegurasse à aceleração um campo de experiência que lhe fosse totalmente adequado". (KOSELLECK, 2006, p.37).

Em sua carta, Maiakóvski tenta apressar esse encontro com o futuro ao descrever as novas e possíveis experiências humanas após a Revolução do Espírito. Ele "salta" no tempo para imaginar como seriam as invenções dos homens e a arte, afirmando que- em um amanhã grandioso- “Talvez os pintores transformem a poeira cinzenta das cidades em arco-

Futuristes), que s'exprima clairement l'exigence des futuristes d'accéder à un statut privilégié dans l'Etat révolutionnaire. Dans ce numéro,- Bourhouk, Kamenski et Maïakovski se déclaraient être les vrais révolutionnaires de l'art et Maïakovski adressait une «Lettre ouverte aux Ouvriers», dans laquelle il raillait l'art ancien encore proposé aux travailleurs, et se prononçait en faveur d'une Révolution spirituelle] 
íris centicores, talvez das cumieiras das montanhas então ressoe sem cessar a música tonitroante dos vulcões transformados em flauta" (MAIAKÓVSKI [1918] 1984, p.120).

Esses saltos, de acordo com Jörn Rüsen caracterizam o pensamento utópico que procura transcender as experiências vividas e superar o conteúdo do passado. As expectativas de Maiakóvski em um futuro que transforme a poeira das cidades negam justamente "a realidade das circunstâncias dadas da vida" (RUSEN, 2007, p. 136 e 137), sejam as catástrofes da guerra ou as do processo revolucionário, projetando transformações no futuro.

[...] Dão-se saltos utópicos para o futuro, que superam sempre o conteúdo factual do passado. É nessa ultrapassagem que reside seu sentido próprio: esses saltos vivificam a esperança e a nostalgia como impulsos importantes da autocompreensão humana e do agir humano transformador. (RUSEN, 2007, p. 136).

No limite, a Carta aberta aos operários descreve todas as características de uma revolução moderna, pois apresenta não só um horizonte de expectativas aberto na Rússia do início do século $X X$, como também a busca dos revolucionários por uma aceleração do tempo e por uma ruptura com os fatos do passado através de ações programadas e conscientes (HOBSBAWM, 1986, p.12). Nesse ambiente, a atuação dos homens na construção de um novo tempo histórico era não só possível, como, acima de tudo, era consciente. Segundo Eric Hobsbawm, a consolidação política dos bolcheviques ocorreu porque, "ao contrário de toda a esquerda, eles estavam prontos para tomar o poder" (HOBSBAWM, 2014, p.74) e porque sua bandeira abarcava uma série de expectativas sobre o futuro que demandavam planejamento e ações concretas.

Como Maiakóvski aposta na criação consciente e planejada de uma nova cultura artística para a superação das referências do passado, para ele, a razão deveria proteger os novos homens dos paradigmas burgueses. A partir da Revolução, estes seriam apenas estudados nas escolas e universidades como velharias sem função prática. "Que a razão vos proteja da coação física contra os restos da antiguidade artística. Entreguem-nos às escolas e 
Uma Carta aberta ao Futuro: Horizontes de expectativa e Revolução em “Carta aberta aos operários" de Vladimir Maiakóvski (1918)

às universidades, para o estudo da geografia, dos costumes e da história [...]", afirma o poeta. (MAIAKÓVSKI [1918] 1984, p.120).

O projeto de Maiakóvski para uma Revolução do Espírito consistia, justamente, na percepção de que a autoconsciência era intrínseca ao movimento e ao discurso revolucionário. Desse modo, ele sugere aos operários: “Disputem com avidez os pedaços de arte sadia, jovem e rude que Ihes entregamos", mas neguem "indignados aquele que lhes oferecer esses objetos petrificados (arte e diversão burguesas) em lugar do pão da beleza viva" (MAIAKÓVSKI, [1918] 1984, p. 120). As "velharias" da música, do teatro e dos poemas burgueses deveriam, portanto, ser claramente rejeitadas, pois não condiziam com o planejamento da nova arte, o futurismo, e com o planejamento da "revolução do conteúdo", ou seja, o socialismo.

A emergência do próprio conceito de socialismo, segundo Koselleck, associa-se à percepção do futuro como novo tempo. Para ele, assim como "republicanismo" e "liberalismo" o "socialismo" teria surgido como um "conceito de movimento", ou seja, como um conjunto de ideias para abarcar as novas expectativas que rompiam com o passado, cujo objetivo seria criar e dar forma a um futuro que não era mais reconhecível, nomeando possibilidades infinitas de experiência (2006). Em suas palavras:

Ao serem criadas, tais expressões possuíam pouco ou nenhum conteúdo de experiência, e de qualquer forma não possuíam o conteúdo a que se aspirava no momento em que o conceito havia sido criado. [...] Do ponto de vista da história social, trata-se de expressões que reagem ao desafio de uma sociedade em via de transformação técnica e industrial. Elas servem para ordenar sob novos lemas as massas que deixavam para trás as sociedades estamentais; delas faziam parte interesses sociais, bem como diagnósticos científicos e políticos. Por isso servem de slogans para a formação de partidos. Desde então, o conjunto do campo linguístico sociopolítico é levado pela tensão progressivamente aberta entre experiência e expectativa. (KOSELLECK, 2006, p.326).

Os que procuraram na Rússia, por fim, transformar as expectativas contidas no conceito de socialismo em experiência concreta tiveram o desafio de manipular o que não conheciam. 


\section{dossiê}

Ana Carolina Lebre dos Santos

Hobsbawm enfatiza os limites do planejamento da ação humana, afirmando a impossibilidade de os homens preverem acontecimentos e consequências específicas, mesmo que busquem identificar suas possibilidades de ação (HOBSBAWM, 2014, p.76). De todo modo, se o futuro era desejável, mas também incerto, Maiakóvski esperava que o a construção de uma nova arte fosse capaz de superar as experiências vividas até então. As ações para isso, em 1918, deviam ser conscientes mesmo que o mundo da Revolução do Espírito não pudesse ser previamente descrito.

Ao se perguntar "Com que edifícios fantásticos" os novos construtores "hão de cobrir o lugar dos incêndios de ontem"? Ou quais "músicas e canções hão de espalhar-se de suas janelas?", Maiakóvski demonstra sua incerteza em relação ao futuro, ao mesmo tempo em que reforça a expectativa de que, de todo modo, ele será fantástico. (MAIAKÓVSKI [1918] 1984, p. 119).

A incerteza, portanto, quanto às reais consequências da Revolução na Rússia e seus próximos passos, não abalou, ao menos de início, a sua convicção de que uma sociedade livre seria o resultado da construção de um novo tempo. Hannah Arendt afirma que durante a Revolução de Outubro, assim como na Revolução Francesa, os revolucionários tiveram de "primeiro cristalizar as melhores esperanças dos homens e depois perceber a extensão completa de seu desespero" (ARENDT, 2011, p. 90). De outro modo, olharam primeiro para o que esperavam do futuro, antes de lidarem com as suas imprevisibilidades.

\section{Os Sóis da vida futura}

Roman Jakobson consegue captar as angústias de um Maiakóvski que, ao mesmo tempo, acreditava na construção consciente do futuro, mas reconhecia a impossibilidade de prevê-lo. (JAKOBSON, 2006, p.20). A esperança de Maiakóvski era, contudo, a de que a possibilidade de atuação dos homens sobre o tempo se desenvolvesse a tal ponto que as barreiras entre ele e o futuro fossem, finalmente, dissolvidas. 
Uma Carta aberta ao Futuro: Horizontes de expectativa e Revolução em “Carta aberta aos operários" de Vladimir Maiakóvski (1918)

Durante uma conversa com Jakobson, Maiakóvski teria afirmado que as novas descobertas de Einstein tornariam possível a ressurreição dos homens. "Pois eu estou inteiramente convencido de que algum dia não existirá mais morte. Vão ressucitar os mortos" (MAIAKÓVSKI apud JAKOBSON, 2006, p.29), sublinhou ele. Essa fé na ação humana sobre o tempo teria levado Maiakóvski a confiar no progresso contínuo e a crer que a relatividade na física seria a chave para que conseguisse vivenciar a revolução completa do futuro e, não apenas, esperá-la no presente.

Na primavera de 1920, voltei a Moscou, então cercada pelo bloqueio. Trazia livros novos da Europa, informações sobre a atividade científica no Ocidente. Maiakóvski fez-me repetir várias vezes meus comentários, um tanto confusos, sobre a teoria geral da relatividade e a discussão que se desenvolvia a respeito na época. A liberação da energia, a problemática do tempo, a questão de saber se uma velocidade que ultrapassa o raio de luz não constitui a marcha inversa no tempo - tudo isso apaixonou Maiakóvski. (JAKOBSON, 2006, p.29).

Os problemas levantados por Einstein foram para Maiakóvski como comprovações de que o homem poderia não só acelerar, como transgredir o tempo. Em vários de seus poemas e textos, a ressureição se torna uma realidade possível e um mecanismo pelo qual os homens podem vivenciar o futuro e escapar de um passado e de um cotidiano insuficientes. No seu “hino ao cientista”, por exemplo, ele celebra e descreve o domínio do homem sobre o tempo.

Obrigarei o tempo a parar e a correr em qualquer direção, a qualquer velocidade.

Os homens poderão sair dos dias, assim como os passageiros dos bondes e dos ônibus [...]. Você pode transformar em redemoinhos os extensos, lentos anos da dor, encolher a cabeça nos ombros; acima de você, sem ferir nem tocar, o projétil do sol haverá de passar cem vezes por minuto, acabando com os dias escuros. (MAIAKOVSKI, apud JAKOBSON 2006, p.32).

Aliadas à arte, a física e a química do futuro garantiriam aos homens o controle sobre sua felicidade e o fim dos "tempos escuros". Ao final de sua carta aos operários, Maiakóvski afirma que a arte e a revolução podem seguir diversos caminhos e que "Talvez obriguemos as ondas dos oceanos a ferir as cordas das redes estendidas entre a Europa e a América". Independentemente disso, sua expectativa era a de que a vida futura fosse iluminada por 
"imensos sóis" e sua certeza era a de estar inaugurando a "primeira página da novíssima história das artes" (MAIAKÓVSKI [1918] 1984, p.120) rumo a um novo tempo, a uma revolução completa.

\section{O esbanjar dos poetas}

Em nome do fim da opressão e da busca pelo controle do futuro, os que apoiaram o processo revolucionário de outubro aderiam à revolução como se ela fosse inevitável. Para Arendt, a Revolução Russa foi a revolução moderna que mais explorou a concepção de que existe uma necessidade história intrínseca ao movimento revolucionário. Como uma necessidade, portanto, a revolução deveria caminhar, mesmo que tivesse de "devorar os próprios filhos" (ARENDT, 2011, p. 90).

Há um certo ridículo grandioso no espetáculo desses homens- que tinham ousado desafiar todos os poderes do mundo e contestar todas as autoridades da terra, cuja coragem estava além de qualquer sombra de dúvida-, passando de uma hora para outra a se submeter humildemente sem sequer uma exclamação de protesto, ao chamado da necessidade histórica, por mais tola e incongruente que lhes parecesse a manifestação externa dessa necessidade. (ARENDT, 2011, p. 91).

Maiakóvski aderiu de imediato à Revolução de Outubro e mobilizou sua arte como ferramenta da propaganda política. Logo no momento da queda do Palácio de Inverno, ele deixou evidente não só a sua certeza em apoiar o movimento, mas a de todo o grupo dos futuristas próximos a ele. "Aceitar ou não aceitar? Semelhante pergunta não existia para mim (e para os demais futuristas moscovitas). Fui ao Smólni ${ }^{7}$. Trabalhei. Tudo o que era preciso. Começavam as reuniões". (MAIAKÓVSKI, [1917] 1984, p. 97).

A Carta aos Operários foi um de seus apelos à continuação das transformações e à destruição dos "palácios luxuosos" que antes impediam a alma do povo de aguardar "uma semeadura grandiosa" (MAIAKÓVSKI [1918] 1984, p. 119). Em 1918, essas esperanças se colocavam adiante da novidade proposta pela revolução. Quando, porém, a experiência do

7 O Smolni era uma escola para moças da nobreza que, durante o processo revolucionário, foi utilizada pelos bolcheviques como quartel-general. (SCHNAIDERMAN, 1984, p.107). 


\section{dossiê}

Uma Carta aberta ao Futuro: Horizontes de expectativa e Revolução em “Carta aberta aos operários" de Vladimir Maiakóvski (1918)

processo revolucionário foi transformando as expectativas sobre a própria revolução, Maiakóvski começou a dissociar o seu futuro de "imensos sóis" da realidade do Partido Comunista russo.

Como pontuado anteriormente, grande parte da esperança de Maiakóvki na Revolução de Outubro estava na possibilidade de que as transformações políticas e sociais fossem concomitantes à consolidação de uma arte inovadora, o futurismo. O problema literário para Maiakóvski não se resumia a um conteúdo revolucionário e combativo, mas se estendia a uma forma inovadora. Dentre os objetivos da poesia futurista, ele destacava em 1922: "revolucionar a sintaxe (simplificação dos agrupamentos vocabulares, incisivo do emprego inusitado e etc)" e "criar modelos surpreendentes de construção de argumento" (MAIAKÓVSKI [1922] 1984, p. 164).

Enquanto criou cartazes, peças teatrais e poemas que impulsionaram a revolução, Maiakóvski serviu à propaganda oficial do Estado Soviético. Contudo, sua preocupação com o formalismo e com a estética começou a incomodar o Comitê Central do Partido Comunista que, em 1928, afirmou ao poeta: "operários e camponeses não compreendem o que você diz" (MAIAKÓVSKI, [1928] 1984, p. 229).

Já nos primeiros anos da revolução, o controle sobre a literatura e a arte produzidas e difundidas passou a ser crucial nas discussões do partido. Em 1925, a comissão literária do Comitê Central divulgou uma resolução na qual estimulava o combate aberto contra todas as concepções literárias que fossem consideradas "neo-burguesas". (ANDRADE, 1997, p. 39). Embora não proibisse a manifestação de artistas de vanguarda, o documento abriu brechas à perseguição de todos os que se enquadrassem na definição pouco precisa de "escritor neoburguês".

Acelerava-se o processo rumo à unidade ideológica no discurso literário. Boatos insistentes sobre a detenção para averiguações de escritores e intelectuais voltavam a circular em Moscou. Delações, perseguições. O controle burocrático e policial sobre o cotidiano dificultava a vida dos artistas ainda 
renitentes, forçando-os a ingressar nas fileiras do exército das artes do proletariado. (ANDRADE, 1997, p. 37).

Escritores que apoiaram os bolcheviques em outubro e mobilizaram sua arte para a continuação do processo revolucionário, começaram a ser perseguidos. Esse é o caso de Maiakóvski que, de poeta da revolução se transformou em um escritor "incompreensível para as massas". O confronto que ele e outros poetas enfrentaram entre suas expectativas na revolução e a experiência após a consolidação do Estado soviético foi mortal para muitos deles. Roman Jakobson enumera vários dos que não resistiram à decepção diante de um futuro que não era o esperado.

O fuzilamento de Gumiliov (1886-1921); a longa agonia espiritual e as insuportáveis torturas físicas que levaram Block (1880-1921) à morte; as privações cruéis e a morte desumana de Khlébnikov (1885-1922); os suicídios anunciados de lêssienin (1895-1925) e Maiakóvski (1893-1930). Assim pereceram, no curso dos anos 20 deste século, na idade de 30 ou 40 anos de idade, os inspiradores de toda uma geração. E cada um deles teve a nítida e insuportável consciência do irremediável. (JAKOBSON, 2006, p. 11).

Em 1918, Maiakóvski escreveu em sua Carta aos Operários que a alma do povo, tanto na Rússia, como no mundo, aguardava "uma semeadura grandiosa" do futuro. Contudo, em sua carta de suicídio (1930), a esperança no amanhã retorna à rotina sufocante do presente, pois “o barco do amor espatifou-se no cotidiano" (MAIAKÓVSKI apud JAKOBSON, 2006, p. 37). Como o futuro em aberto não completou a Revolução do Espírito, Maiakóvski viu no suicídio a sua única opção.

Maiakóvski foi destruído pela destruição do futuro, daquele futuro para o qual se lançara desde os tempos do futurismo. Ele, que esbofeteara o filisteísmo burguês pré-revolucionário, viu-se rodeado, depois da Revolução, por um filisteísmo agigantado, que já não se deixava esbofetear e contra- atacava com uma agressividade cruel. (ANDRADE, 1997, p. 47).

A experiência das revoluções modernas anteriores permitiu que os revolucionários na Rússia projetassem no futuro um tempo, não só diferente do passado, mas melhor. As expectativas envoltas no processo revolucionário de 1917 são, na verdade, intrínsecas à 
Uma Carta aberta ao Futuro: Horizontes de expectativa e Revolução em “Carta aberta aos operários" de Vladimir Maiakóvski (1918)

"abreviação do passado" (MEYERHOFF, 1976, p. 95) e às transformações na percepção de tempo, características do mundo moderno.

O descompasso entre a expectativa de Maiakóvski no início da revolução e seu suicídio em 1930 é apenas um dos exemplos do quanto o curso do futuro se tornou irreconhecível para os homens, mesmo para os que procuraram planejá-lo e construí-lo. Como conclui Hobsbawm,

Como tanta coisa do futuro prevista no passado, quando vier pode ser irreconhecível, não porque as previsões estivessem erradas, mas porque estávamos enganados ao colocar uma determinada face e roupagem no curioso estranho cuja chegada nos disseram para esperar. (HOBSBAWM, 2014, p.84).

Em 1927, Maiakóvski ainda sustentava, mas agora com incerteza, que o futuro de "imensos sóis" era possível. "Para mim tudo ainda está por vir. Se eu pensasse que o melhor de mim está no passado, isto seria o fim", afirmou ele a Jakobson. (MAIAKÓVSKI apud JAKOBSON, 2006, p. 41). De fato, a desesperança total para Maiakóvski foi deixar de reconhecer o seu futuro na revolução, de projetar nela, "uma semeadura grandiosa" ou de, simplesmente, como coloca Jakobson, ter a certeza de que o futuro não Ihe pertencia.

O futuro também não nos pertence. Daqui a algumas dezenas de anos, seremos chamados, sem qualquer piedade, de gente do milênio passado. Tínhamos apenas cantos apaixonantes sobre o futuro e, de repente, esses cantos, frutos da dinâmica do presente, transformaram-se em fatos da história literária (JAKOBSON, 2006, p 53).

O futuro, que estava em aberto desde o final do século XVIII, aparecia para Maiakóvski e outros poetas e revolucionários na Rússia do início do século XX como um horizonte possível de transformação e aperfeiçoamento da felicidade dos homens. No entanto, como define Koselleck,

Horizonte quer dizer aquela linha por trás da qual se abre no futuro um novo espaço de experiência, mas um espaço que ainda não pode ser contemplado. A possibilidade de se descobrir o futuro, apesar de os prognósticos serem 
possíveis, se depara com um limite absoluto, pois ela não pode ser experimentada. (KOSELLECK, 2006, p. 312).

Essa impossibilidade de que as expectativas sobre o futuro, sejam elas de esperança ou de desilusão, consigam prever as situações e as próprias experiências ao longo da história faz com que elas sejam constantemente revistas. "As velhas expectativas se desgastam nas novas experiências" (KOSELLECK, 2006, p.326). As esperanças de Maiakóvski se contraíram diante das censuras do Comitê Central e a trajetória da revolução entrou em confronto com as várias previsões que tinham sido feitas sobre ela. Cabe aos historiadores, por fim, que ultrapassam o limite das expectativas, pois conhecem as experiências do passado, compreenderem essas relações, esperanças ou desesperanças que levaram Maiakóvski e outros revolucionários a agir sobre e no seu próprio tempo.

\section{Fonte:}

MAIAKÓVSKI, Vladimir. Carta Aberta aos Operários. In: SCHNAIDERMAN, Boris. A poética de Maiakóvski, São Paulo: Perspectiva, 1984. p.119-120.

\section{Referências bibliográficas:}

ANDRADE, Homero Freitas de. A Literatura que Stalin proibiu. In: Revista de Estudos Orientais, n.1, p.33-53, março, 1997. Disponível em: https://www.revistas.usp.br/reo/article/view File/90646 Acesso em: 06 dez. 2017.

ARENDT, Hannah. Sobre a Revolução. São Paulo: Companhia das Letras, 2011.

CHERMAN, Alexandre; VIEIRA, Fernando. O tempo que o tempo tem: por que o ano tem 12 meses e outras curiosidades sobre o calendário. Rio de Janeiro: Jorge Zahar, 2008.

HOBSBAWM, Eric. A história e a previsão do futuro. In: Sobre História. São Paulo: Companhia de Bolso, 2014, p. 61-85.

. Revolution. In: PORTER, Roy; TEICH, Mikulás. Revolution In Hystory. Cambridge: Cambridge University, 1986.

JAKOBSON, Roman. A geração que esbanjou seus poetas. São Paulo: Cosac Naify, 2006.

KOSELLECK, Reinhart. Futuro Passado: contribuição à semântica dos tempos históricos, Contraponto. Rio de Janeiro: Ed. PUC-Rio, 2006.

MEYERHOFF, Hans. O tempo na literatura. São Paulo: Mc-Graw-Hill do Brasil, 1976. 


\section{dossiê}

Uma Carta aberta ao Futuro: Horizontes de expectativa e Revolução em "Carta aberta aos operários" de Vladimir Maiakóvski (1918)

POZNANSKI, Renée. V. Maïakóvski, la révolution politique, instrument de la révolution dans l'art. In: L'Homme et La société, n. 59-62, 1981. Imaginaire sociale et créativité, p. 103-129. Disponível em: http://www.persee.fr/doc/homso_0018-4306_1981_num_59_1_3169. Acesso em 20 out. 2017.

RÜSEN, Jörn. História viva: teoria da história: formas e funções do conhecimento histórico. Brasília: Ed. Universidade de Brasília, 2007.

SCHNAIDERMAN, Boris. A poética de Maiakóvski, São Paulo: Perspectiva, 1984.

WHITROW, G. J. O tempo na história: concepções sobre o tempo da pré-história aos nossos dias. Rio de Janeiro: Jorge Zahar, 1993. 